\section{Challenges and Achievements in Founding an Open Access Journal on Educational Leadership and Research Use}

\author{
Dan Laitsch \\ Simon Fraser University \\ Elizabeth Farley-Ripple \\ University of Delaware \\ Jenice View \\ George Mason University
}

Scholarly and Research

Communication

VOLUME 10 / ISSUE 2 / 2019

\begin{abstract}
The International Journal of Education Policy and Leadership (IJEPL) published its first article on June 5, 2006, and has been releasing articles steadily since. With more than 300,000 article downloads and 104 published articles across 13 volumes, IJEPL has established itself as an important contributor to open access research publishing in the field of education. Initially published as a collaborative partnership among faculty at Simon Fraser University, George Mason University, and ASCD (a global professional development organization and publisher for education professionals), the journal has faced (and overcome) a number of key challenges in its 13-year history.
\end{abstract}

Keywords Education; Leadership; Policy; Research use

\section{Résume}

L'International Journal of Education Policy and Leadership (IJEPL) a publié son premier article le 5 juin 2006 et depuis lors il fait régulièrement paraître divers articles. Avec 104 articles en 13 volumes et plus de 300 ooo téléchargements, IJEPL s'est établi comme un contributeur majeur à lédition en libre accès de la recherche en éducation. Initialement édité en partenariat par le corps professoral de Simon Fraser University, George Mason University et ASCD (organisme mondial de développement professionnel ainsi quéditeur pour les professionnels en éducation), la revue a fait face à de nombreux défis clés (qu’elle a surmontés) au cours de ses treize années d’existence.

Mots clés Éducation; Leadership; Politiques; Utilisation pour la recherche

\section{CISP Press}

Scholarly and Research Communication

Volume 10, Issue 2, Article ID 1001309, 10 pages

Journal URL: www.src-online.ca http://doi.org/10.22230/src.2019v10n2a309

Received September 9, 2018, Accepted February 17, 2019, Published March 5, 2019

Laitsch, Dan, Farley-Ripple, Elizabeth, \& View, Jenice. (2019). Challenges and Achievements in Founding an Open Access Journal on Educational Leadership and Research Use. Scholarly and Research Communication, 10(2): 1001309, 10 pp.

() 2019 Dan Laitsch, Elizabeth Farley-Ripple, \& Jenice View. This Open Access article is distributed under the terms of the Creative Commons Attribution Non-Commercial License (http://creative commons.org/licenses/by-nc-nd/2.5/ca), which permits unrestricted non-commercial use, distribution, and reproduction in any medium, provided the original work is properly cited.
Dan Laitsch is an Associate Professor in educational leadership at Simon Fraser University. He is affiliated with the SFU Centre for the Study of Educational Leadership and Policy and is active in the American Educational Research Association Special Interest Group on Research Use. He is a co-founding editor of IJEPL. Email: dlaitsch@sfu.ca

Elizabeth Farley-Ripple is an Associate Professor of education and public policy at the University of Delaware. Her research focuses on educational policy and leadership, organizational improvement, and capacity building at the school and district levels. Email:

enfr@udel.edu

Jenice View is an Associate Professor in the Educational Transformation Program at George Mason University. Her scholarship focuses on the critical teaching and learning of history, critical pedagogy in teacher professional development, arts and arts integration, and how learning history impacts youth voice and civic engagement. Email: jview@gmu.edu 


\section{Scholarly and Research}

\section{Communication}

VOLUME 10 / ISSUE 2 / 2019

\section{Introduction}

The International Journal of Education Policy and Leadership (IJEPL) is an online-only, peer-reviewed, fully open access publication focused on empirical research on education policy, education leadership, and research utilization. Articles submitted to IJEPL go through a double-blind review process (neither the authors nor the reviewers are known to each other) and are evaluated for methodological strength as well as presentation quality. All articles undergo professional copy-editing and layout. There are no article processing charges; all funding comes from the volunteer labour of the partner organizations - Simon Fraser University (SFU), the University of Delaware, George Mason University (GMU), and Phi Delta Kappa International - and the editorial review board, with financial support provided by the Canadian Social Sciences and Humanities Research Council (SSHRC) and the William T. Grant Foundation. The SFU Library hosts the journal, and it is published on the Open Journal System (OJS) platform.

\section{Journal history: A creative collaboration}

The International Journal of Education Policy and Leadership was born from failure. While this may seem like an ignominious opening, it stands as testimony to the commitment of the founding editors (Penelope Earley and Dan Laitsch) to open access and to the free dissemination of research to inform education policy and leadership. We believed (and still do) that practitioners, policymakers, and education leaders need free access to high-quality research if they are to be expected to engage in research-based practice, design strong policy, and lead from a solid foundation of knowledge.

We first sought to act on this commitment when the editorship opened at of one of the seminal open access education journals: Education Policy Analysis Archives (EPAA), which was established in 1993 by founding editor Gene Glass. The journal was looking to transition to new editors in 2004, and we applied to take on that work. While our bid to edit EPAA failed, it laid the foundation for our proposal to establish IJEPL with the ASCD.

In 2004, the ASCD decided to end the publication of its scholarly journal, the Journal of Curriculum and Supervision (JCS) after 20 volumes. As a membership organization and publisher, the ASCD is concerned with both the member value of its products and their return on investment. As a result, products are routinely reviewed for cost and usage. While the ASCD could count its membership base at the time in the hundreds of thousands, the post-secondary membership was a small fraction of that, and the number of members subscribing to JCS was even smaller. The journal was also fairly expensive to produce, as the ASCD funded an editorial board meeting at its annual conference, managed submissions, copy-edited and formatted all articles, and published print versions for subscribers. Finally, as a peer-reviewed journal, JCS editorial decisions were outside of the control of the organization. The confluence of these factors likely contributed to the decision to end publication. In hindsight, JCS may also have been caught in the changing business model of journal publishing, which saw journals moving from an individual print-subscription model to an institutional digital-subscription model (National Research Council, 2004; Waltham, 2006). In proposing IJEPL, we made the case that the association needed to maintain a public commitment to peer-reviewed research, and that the potential cost savings in moving from print to digital production and the increased access to a global market would

Laitsch, Dan, Farley-Ripple, Elizabeth, \& View, Jenice. (2019). Challenges and Achievements in Founding an Open Access Journal on Educational Leadership and Research Use. Scholarly and Research Communication, 10(2): 1001309, 10 pp. 
assuage the ASCD's concerns. Ultimately, we were able to convince the leadership that it would be worth experimenting with open access and the new technologies that were building an open access revolution, such as OJS. As it turns out, the challenges faced by JCS in 2006 foreshadowed the challenges IJEPL was to face seven years later in 2013.

The initial collaboration with the ASCD was built on the belief that a small amount of resources from each partner institution could result in sufficient support to establish and maintain a high-quality research journal. In this model, GMU coordinated peer review and the initial processing of articles, the ASCD and its strong publishing department contributed copy-editing and design, and SFU, with its links to the Public Knowledge Project (PKP) and the associated OJS, contributed hosting, technical support, and article formatting and layout. The ASCD also continued to fund travel, hosted a meeting of the editorial board (Penelope Earley, Dan Laitsch, and the ASCD staff), and presented research from the journal at its annual conference. As will be demonstrated, our belief that a small amount of resources from each institution could support a high-quality research journal was both right and wrong.

\section{Management and technology}

To ensure quality, articles published in IJEPL undergo double-blind peer review. While we initially worried about gaining access to quality content, we quickly discovered that the challenges of running a peer-reviewed research journal were seldom related to the content of the articles. Receiving timely reviews from peers, training graduate students as reviewers and editors, and dealing with graduate student turnover were unexpected challenges. Although our professional partner, the ASCD, copy-edited and promoted the journal, we were also responsible for article layout and the hosting on the OJS system, which turned out to be more labour-intensive than expected.

While the OJS provides the backbone of our publishing process, learning the system and keeping abreast of changes to the software - as well as learning about (and incorporating) new opportunities in technology - also proved to be labour-intensive and time-consuming, even as it was necessary for ensuring journal quality.

\section{Quality and integrity}

While these management issues were time-consuming, we faced our first major operational hurdle in 2013. As part of its product-review cycle, the ASCD decided to withdraw from the partnership. While this decision was internal, it seems likely that the collaboration was ended for many of the same financial reasons that JCS was dropped. This break cast us into turbulent times, as we needed to add copy-editing to our editorial responsibilities. Of more importance to the life of the journal, however, was the danger that the loss of a professional partner would both limit the reach of the articles and leave IJEPL afloat in a sea of questionable credibility. With the increasing exposure of predatory journals, we felt it critical to maintain a relationship with the profession through linkages with a strong membership organization. As a result, 2014 was spent largely reaching out to other professional education bodies to rebuild a linkage with the field. While we engaged with a number of professional associations, we ultimately reached an agreement to link with Phi Delta Kappa (PDK) and its global network of educators. Phi Delta Kappa is a membership association of primarily K-12 educators

Laitsch, Dan, Farley-Ripple, Elizabeth, \& View, Jenice. (2019). Challenges and Achievements in Founding an Open Access Journal on Educational Leadership and Research Use. Scholarly and Research Communication, 10(2): 1001309, 10 pp. 


\section{Scholarly and Research}

Communication

VOLUME 10 / ISSUE 2 / 2019 and education leaders, and publisher of Kappan magazine, a professional publication focused on governance and school improvement. The partnership links IJEPL's research with PDK's membership base and provides a potential bridge between researchers and practitioners.

Another challenge the journal has faced in setting itself apart as a high-quality research journal relates to its place within the publishing realm. As a single journal publication, IJEPL has maintained a small but consistent publication frequency, averaging just over eight articles per year, with an acceptance rate of about 12 percent over the life of the journal. While we have been part of the EBSCO databases since 2009 and are listed in the ERIC Institute of Information Services database, we also sought listings in the Web of Science and Google Scholar as part of our commitment to excellence.

Unfortunately, we soon learned that we were too small to be listed in their databases, as the Web of Science (from Thompson Reuters) required electronic journals to publish a minimum of 15 articles in nine months, or 20 articles across 12 months. This is somewhat ironic in that journal impact factors were developed in part to ensure smaller publications were not lost among the larger publishing journals (Garfield, 2006). At the time Google Scholar required at least ten articles be published each year over a threeyear period - now it requires 100 articles over five years (Google Scholar, n.d.). While our articles are listed individually in Google Scholar, the journal is not, meaning we cannot generate an $\mathrm{H}$-factor (or other quality metrics). To strengthen our quality profile, we would have had to accept articles our reviewers rejected, which we chose not to do.

\section{Stability and funding}

We also worked hard to institutionalize the journal and obtain steady funding. Initially, GMU funded a graduate student position to support the journal, the ASCD funded article copy-editing, and SFU provided Web hosting, but all of the initial production, editorial, and review labour relied on volunteers. Some of this work was supported by small, occasional internal publishing grants from SFU (and indeed this was critically important after the ASCD left), but that funding was never intended to be ongoing.

As a result, we explored multiple revenue-generation possibilities, including inviting user donations, selling subscriptions, and adopting publications fees, but ultimately rejected all of those options. We quickly saw the problem with publication fees and the strong incentives in place that gave rise to the predatory publishing industry (XIA, 2015) and wanted to make sure to steer clear of that area.

Ultimately, we decided to seek support in the form of grants for scholarly publishing from Canada's Social Sciences and Humanities Research Council (SSHRC), which has a grant program, Aid to Scholarly Journals, designed to support research publications in Canadian institutions. We first applied to the fund in 2007 but missed the deadline as we completed the electronic application, but failed to print and mail the submission in time to meet the deadline. We applied again in 2011, but we were turned down as reviewers were unsure how to adjudicate an open access-only journal. We finally put forth a successful application in 2014. The funds provided have radically changed the journal and allowed us to bring on SFU's publishing department to support copy-editing, article lay-

Laitsch, Dan, Farley-Ripple, Elizabeth, \& View, Jenice. (2019). Challenges and Achievements in Founding an Open Access Journal on Educational Leadership and Research Use. Scholarly and Research Communication, 10(2): 1001309, 10 pp. 
out, and website redesign, and to revise the article template. The funds have allowed us to take advantage of changing technology regarding the OJS and services such as article archiving with LOCKSS and the use of Digital Object Identifiers (DOIs). As a result, we have been able to shift our focus from production to expansion and quality control.

\section{Recent history and institutionalization}

Once we established consistent funding and re-established ties to the profession, we turned our focus to addressing a few of the niggling issues highlighted earlier: expanding our publication frequency (and concomitantly expanding access to high-quality research submissions) and strengthening our peer-review capacity.

One of the goals of the journal has long been to increase article production to a level that would allow us to broaden the reach and impact of our work. As noted earlier, one of the key aspects of our commitment to open access relates to the use of research to inform policy and practice. This interest led to a natural collaboration with the Special Interest Group for Research Use (SIGRU) at the American Education Research Association (AERA).

In 2014-2015, the officers of SIGRU were interested in starting a new journal on research use and began to explore mechanisms to do so. After putting together a proposal for the SIGRU members to adopt, they learned that AERA policies prohibited special interest groups (SIGs) from creating their own journals.

At the same time, IJEPL editors were looking for expanded linkages with potential authors and readers; closer ties with AERA, the premier education research association in the U.S., seemed like a good place to build those linkages. As IJEPL editors were also active SIGRU members, we knew about (and were part of) the effort to launch the Research Use journal. When that effort failed, we were able to bring the SIG officers and IJEPL editors together to add a Research Use section to IJEPL. Launched in 2015, Research Use has seen its articles making their way into the publication stream, and they have already had an impact on increasing both our publication numbers and readership.

To further increase IJEPL's reach and publication frequency, we have also begun publishing special issues, focusing on topics targeted to high-priority areas for authors and readers. Our first special issue, focusing on research in the Canadian context, was released in early 2019 with 11 articles, likely doubling our output for the year. Our second special issue is targeted for late 2019-early 2020. We estimate these changes will increase our article publication counts to the numbers needed for inclusion in the Web of Science and Google Scholar.

The final phase of our growth includes an ending and a beginning. Penelope Earley, cofounding editor of IJEPL, retired from GMU and IJEPL in the summer of 2018 . Her retirement was a great loss to the journal and resulted in the remaining two editors looking anew at the journal structure with an eye toward building capacity and succession planning. Jenice View stepped into Dr. Earley's role as the editorial partner from GMU and the three editors decided to establish an editorial review board to strengthen our relationship with our reviewers, better recognize the important work they do, and

Laitsch, Dan, Farley-Ripple, Elizabeth, \& View, Jenice. (2019). Challenges and Achievements in Founding an Open Access Journal on Educational Leadership and Research Use. Scholarly and Research Communication, 10(2): 1001309, 10 pp. 


\section{Scholarly and Research}

Communication

VOLUME 10 / ISSUE 2 / 2019 build a set of partnerships that could contribute to longer-term succession planning for the journal. The inaugural board was established in the summer of 2018 and will have its first collective meeting at the 2019 AERA annual meeting.

The ASCD's change in direction and Dr. Earley's retirement also highlighted a final issue IJEPL faces as a small, independent journal: long-term institutionalization. The driving force behind the journal has been the individual commitment of the editors to providing an open access research journal in leadership, research use, and policy.

Because the model is based on ideas and partnerships rather than ownership, no single entity accepts full responsibility for the journal, and that includes the mandate for ongoing publication. While this independence carries with it substantial benefits in the form of editorial independence, it also means that we can publish only so long as we have interested readers, authors, reviewers, and editors, as well as steady funding. Our move to obtain stable funding was an important step in our long-term planning, as was the partnership with PDK. The establishment of the editorial review board has also provided a more formal base of scholars to support our ongoing work. That said, this tension between the safety of having an institutional home and the independence of being a stand-alone journal is a challenge that the editors will need to address as they consider long-term succession planning.

\section{Contribution to the field}

For a small journal, measuring impact on the field can be a challenge. As noted earlier, both Google Scholar and the Web of Science require publication frequencies that exclude small journals. The exclusivity of access to these impact factors has, in part, resulted in the rise of organizations creating their own impact factors in an attempt to increase credibility. This has created another market niche for predatory institutions interested in selling substitute impact factors (Jalalian, 2015). Another recent development in adjudicating research quality is the use of altmetrics. These are measures of research access culled from the internet, grey literature, and social networking apps. Here too there are fee-based organizations who will provide data to institutions and researchers (such as Altmetric), as well as nonprofit and open access providers such as ScienceOpen. Navigating this wealth of services and separating the bona fide providers from the predatory ones is a real challenge given the developing nature of the field.

As a journal, IJEPL has struggled to determine the best way to measure impact for external audiences while also trying to maintain integrity and avoid the trap of easy solutions from predatory providers. At its most basic, IJEPL is concerned with its presence on the web - as an open access journal, the more webpages referencing the journal, the broader its reach. A simple Google search for the journal returns more than 85,000 pages and 30,000 Web links to IJEPL. While most of our readers find IJEPL through Web links, the largest single source of readers (over a third) come to us from direct links - that is bookmarks or typing in the Web address directly. Additionally, even though we do not require subscriptions to access content, IJEPL has 2,482 registered readers (subscribers), suggesting that we have a solid repeat user base.

While reach and use is important, measuring actual scholarly impact can be challenging. As a relatively young journal without the benefit of an established impact factor, we need

Laitsch, Dan, Farley-Ripple, Elizabeth, \& View, Jenice. (2019). Challenges and Achievements in Founding an Open Access Journal on Educational Leadership and Research Use. Scholarly and Research Communication, 10(2): 1001309, 10 pp. 
to develop our own methods for establishing quality. One method we use is looking at the citation counts by individual article, which are available in Google Scholar (for 85 of our articles). As of August 2018, IJEPL articles available in Google Scholar have been cited almost 1,600 times, with the top 10 articles cited almost 700 times (see Table 1).

\section{Table 1: Article citation counts from Google Scholar}

\begin{tabular}{|l|r|}
\hline Article title & $\begin{array}{c}\text { Number of } \\
\text { citations }\end{array}$ \\
\hline $\begin{array}{l}\text { The Effects of Education Accountability on Teachers: Are Policies Too } \\
\text { Stress-Provoking for Their Own Good? }\end{array}$ & 154 \\
\hline $\begin{array}{l}\text { The Unintended, Pernicious Consequences of “Staying the Course" on the } \\
\text { United States' No Child Left Behind Policy }\end{array}$ & 88 \\
\hline $\begin{array}{l}\text { Principal Leadership in New Teacher Induction: Becoming Agents of } \\
\text { Change }\end{array}$ & 78 \\
\hline $\begin{array}{l}\text { Rankings of International Achievement Test Performance and Economic } \\
\text { Strength: Correlation or Conjecture }\end{array}$ & 77 \\
\hline Recruiting New Teachers to Urban School Districts: What Incentives Will Work? & 71 \\
\hline $\begin{array}{l}\text { Factors that Promote Progression in Schools Functioning as Professional } \\
\text { Learning Community }\end{array}$ & 66 \\
\hline Teacher and Administrator Perceptions of Bullying in Schools & 51 \\
\hline $\begin{array}{l}\text { Improving Student Achievement: Can 9th Grade Academies Make a } \\
\text { Difference? }\end{array}$ & 45 \\
\hline The Role of Isolation in Predicting New Principals' Burnout & $\mathbf{6 9 1}$ \\
\hline Outdoor Play and Learning: Policy and Practice & \\
\hline Total & \\
\hline
\end{tabular}

Also of interest are the journals in which these citations occur, particularly those that have impact factors of their own. Articles from IJEPL are referenced in dozens of journals, including the flagship journals of the American Educational Research Association and the Canadian Association for the Study of Educational Administration (see Table 2).

Table 2: Sampling of journals with articles referencing IJEPL articles

\begin{tabular}{|l|r|}
\hline Journals citing IJEPL articles & $\begin{array}{c}\text { Journal } \\
\text { impact factor }\end{array}$ \\
\hline Educational Psychology Review & 4.797 \\
\hline Educational Researcher & 4.000 \\
\hline Journal of Teacher Education & 3.180 \\
\hline Journal of Special Education & 2.755 \\
\hline Educational Evaluation and Policy Analysis & 2.486 \\
\hline American Educational Research Journal* & 2.462 \\
\hline Research Evaluation & 2.449 \\
\hline Education Finance and Policy & 2.103 \\
\hline Anxiety, Stress \& Coping & 2.064 \\
\hline Educational Administration Quarterly & 1.850 \\
\hline Canadian Journal of Educational Administration and Policy & $\mathrm{n} / \mathrm{a}$ \\
\hline
\end{tabular}

Notes: ${ }^{*}$ Flagship journals of the American Education Research Association (AERA); ${ }^{*}$ Flagship journal of the Canadian Association for the Study of Educational Administration

Laitsch, Dan, Farley-Ripple, Elizabeth, \& View, Jenice. (2019). Challenges and Achievements in Founding an Open Access Journal on Educational Leadership and Research Use. Scholarly and Research Communication, 10(2): 1001309, 10 pp. 


\section{Scholarly and Research}

\section{Communication}

VOLUME 10 / ISSUE 2 / 2019
Ultimately, however, the quality of the work IJEPL publishes rests on the quality of the research done. While various proxies can be used to suggest quality (from peer review to reader counts to citation counts and impact factors), each measure has its own drawbacks, and is, as pointed out, only a proxy measure of quality. As an open access journal, we see the free, open, and direct access and evaluation of the research content by our readers as the most truly reliable indicator. When visitors read our research, do they see work that is professionally presented, methodologically rigorous, and analytically complete? We cannot answer those question for you, and instead encourage you to access our content and decide for yourself.

\section{Lessons learned}

We decided to share our experience to help other scholars thinking of starting their own journal or taking over the editorship of an established journal. The lucrative field of scholarly publishing is undergoing a time of chaotic transformation brought on by the advent of open access journals and online publishing. The market has changed radically, as has the way we access and read research - moving from in-depth engagement with journals we subscribe to, to broadly accessing articles from dozens (or hundreds) of journals catalogued in online databases. Free public access and institutional subscriptions to large research databases has shifted the funding model from an individual subscriber base to a model funded by research libraries and the researchers themselves. The demands to publish, and pay journal publishers for the service, has helped create the window for predatory publishers. This shift is currently challenging the position of existing scholarly presses and has the potential to expand to academic organizations and their conferences.

With the market model changing, individual journal publishers (and researchers) need to find new models for funding. Journals are no longer the revenue generators they may once have been for membership organizations (as demonstrated by our experience with the ASCD), nor do they offer the solid member benefit they once did, as these publications are now made available to researchers outside of the associations through online library databases.

As faculties have grown and institutional mandates have expanded, research productivity - and the demand to published - has expanded as well. One of the problems we have not faced is access to quality content. Throughout the life of the journal, the number of quality research articles we have received has matched, or even exceeded, our capacity to publish, despite a highly selective acceptance rate of about 14 percent.

Our selectivity highlights another challenge we have faced in working with potential authors. Many authors, when invited to revise their articles and resubmit, choose not to. This has been an interesting issue to experience, as generally we want to work with authors to publish their work, and it suggests that we as editors need to do a better job of communicating to improve our resubmission rate.

The last two lessons learned are related to the rapidly changing technology. Shifting from print to digital delivery has brought with it a host of opportunities: no cost-driven need to limit article length, the ability to archive raw research data associated with arti-

Laitsch, Dan, Farley-Ripple, Elizabeth, \& View, Jenice. (2019). Challenges and Achievements in Founding an Open Access Journal on Educational Leadership and Research Use. Scholarly and Research Communication, 10(2): 1001309, 10 pp. 
cles, and the ability to include video and audio files (for example). It also brings a host of challenges: How do you archive content that does not exist in hard copy? How do you demonstrate journal quality when anyone with a website can publish a journal? How can you demonstrate quality peer review when the tradition is to blind review articles?

Keeping up with the rapid pace of new technology is a challenge on its own. Keeping up with the impact of technology on the work we do is an even greater challenge. Some journals are now eliminating blind peer review and moving to public community review, making the scholarship of revision a public exercise. Online-only publication is expanding the number of articles traditional print publications can release and creating interesting hierarchies and markets within markets for research dissemination. Trying to stay in front of both the technology and the evolving opportunities that technologies offers us in publishing are two of our biggest challenges. What technology should we adopt, and how fast should we embrace the creativity that technology affords us in publishing and peer review?

\section{Conclusion}

This article explored our journey with IJEPL as we worked to find a comfortable place in the field of education publishing; ensure timely and quality peer review; secure adequate staffing and reliable funding; navigate the changing online-publishing environment; maintain space at the leading edge of publishing technology; and never sway from our commitment to freely publish high-quality, open access education research.

This is very much still a work in progress; we expect it to remain so throughout the coming years as the publishing industry continues to explore what it means to publish research in the internet era. We see substantial changes coming to research publication: changes in peer review, article presentation, reader engagement, and commitment to presentation in the public sphere. We see turbulence generated by predatory publishers, conferences, and "scholarly" organizations - yet we also see increased opportunity to democratize knowledge, share research, break down unnecessary barriers to publication and access, and strengthen the place of science and research in our body politic. Our energy and commitment to freely accessible high-quality research that can be used to inform policy and practice in education remains strong, and we are excited to see what the future brings.

\section{Websites}

Altmetric, https://www.altmetric.com/

American Educational Research Association (AERA), https://www.aera.net/

ASCD, http://www.ascd.org/

Canadian Association for the Study of Educational Administration, https://csse-scee.ca/

EBSCO, https://www.ebsco.com/

ERIC Institute of Information Services, https://eric.ed.gov/

Google Scholar, https://scholar.google.ca/

International Journal of Education Policy and Leadership (IJEPL), http://www.ijepl.ca

Kappan magazine, https://www.kappanonline.org/

Phi Delta Kappa International, https://pdkintl.org/

Science Open, https://www.scienceopen.com/ 
Scholarly and Research

\section{Communication}

VOLUME 10 / ISSUE 2 / 2019

\section{References}

Garfield Eugene. (2006). The history and meaning of the journal impact factor. JAMA, 295(1), 90-93. doi:10.1001/jama.295.1.90

Google Scholar. (n.d.). Google Scholar metrics. URL: https://scholar.google.com/intl/en/scholar/metrics.html\#coverage [August 29, 2018].

Jalalian, Mehrdad. (2015). The story of fake impact factor companies and how we detected them. Electronic Physician, 7(2), 1069-1072. URL: http://doi.org/10.14661/2015.1069-1072

National Research Council. (2004). Electronic scientific, technical, and medical journal publishing and its implications: Proceedings of a symposium. Washington, DC: The National Academies Press. doi:10.17226/10983.

Waltham, Mary. (2006). Learned society business models and open access: Overview of a recent JISC-funded study. Learned Publishing, 19(1), 15-30. doi:10.1087/095315106775122529

XIA, J. (2015). Predatory journals and their article publishing charges. Learned Publishing, 28(1), 69-74. doi:10.1087/20150111 